\title{
Shift in the Balance between Excitation and Inhibition during Sensory Adaptation of S1 Neurons
}

\author{
Jaime E. Heiss, ${ }^{*}$ Yonatan Katz, ${ }^{\star}$ Elad Ganmor, and Ilan Lampl \\ Department of Neurobiology, Weizmann Institute of Science, Rehovot 76100, Israel
}

\begin{abstract}
Sustained stimulation of sensory organs results in adaptation of the neuronal response along the sensory pathway. Whether or not cortical adaptation affects equally excitation and inhibition is poorly understood. We examined this question using patch recordings of neurons in the barrel cortex of anesthetized rats while repetitively stimulating the principal whisker. We found that inhibition adapts more than excitation, causing the balance between them to shift toward excitation. A comparison of the latency of thalamic firing and evoked excitation and inhibition in the cortex strongly suggests that adaptation of inhibition results mostly from depression of inhibitory synapses rather than adaptation in the firing of inhibitory cells. The differential adaptation of the evoked conductances that shifts the balance toward excitation may act as a gain mechanism which enhances the subthreshold response during sustained stimulation, despite a large reduction in excitation.
\end{abstract}

Key words: barrel cortex; sensory adaptation; layer 4; conductance measurement; intracellular recordings in vivo; inhibition

\section{Introduction}

In somatosensory and auditory cortical areas, sensory stimulation often activates a stereotypical pattern of excitation, followed a few milliseconds later by inhibition (Wehr and Zador, 2003; Mittmann et al., 2005; Wilent and Contreras, 2005; Higley and Contreras, 2006). Recently, a similar sequence of activation was also reported for spontaneous activity (Okun and Lampl, 2008). Feedforward inhibition is believed to limit the time window for integration of excitation and thus to govern both the rate and the timing of cortical firing. However, the mechanisms that determine the relative contributions of excitation and inhibition to neuronal activity and their dependency on past stimulation history are not clear.

Upon whisker stimulation, excitatory pyramidal neurons, spiny stellate cells and local inhibitory interneurons in layer 4 of the barrel cortex receive excitation from the ventral posterior medial nucleus (VPM) of the thalamus (Porter et al., 2001; Beierlein et al., 2003; Bruno et al., 2003; Swadlow, 2003; Bruno and Sakmann, 2006; Sun et al., 2006; Cruikshank et al., 2007). Although recurrent excitation from other cortical cells is likely to contribute to the response of neurons in primary sensory areas (Douglas et al., 1995; Stratford et al., 1996; Lübke et al., 2000; Liu et al., 2007), when compared with feedforward thalamic excita-

Received June 10, 2008; revised 0ct. 23, 2008; accepted 0ct. 27, 2008.

This work was supported by grants from the Israel Science Foundation (1037/03,326/07), the National Institute for Psychobiology in Israel, the Henry S. and Anne Reich Research Fund for Mental Health, the Asher and Jeanette Alhadeff Research Award, and the Sir Charles Clore fellowship. We thank Valerie Mazig for her help with the histological reconstructions, Michael Okun for his assistance with data processing, and Daniel Dothan for his comments on this manuscript.

*J.E.H. and Y.K. contributed equally to this work.

Correspondence should be addressed to Dr. llan Lampl, Department of Neurobiology, Weizmann Institute of Science, 76100 Rehovot, Israel. E-mail: ilan.lampl@weizmann.ac.il.

DOI:10.1523/JNEUROSCI.2646-08.2008

Copyright $\odot 2008$ Society for Neuroscience ～0270-6474/08/2813320-11\$15.00/0 tion, the inhibitory pathway must involve an additional synapse. However, the effect of repetitive whisker stimulation on the relative contribution of the evoked conductances is unclear.

Rats gather tactile information by sweeping their whiskers against objects at a rate of 5-20 Hz (Carvell and Simons, 1990; Ahissar et al., 2001; Knutsen et al., 2006), and at even higher frequencies during foveal whisking (Berg and Kleinfeld, 2003). At this frequency range, VPM firing achieves a steady state after only a few whisker deflections (Hellweg et al., 1977; Sosnik et al., 2001; Hartings et al., 2003; Khatri et al., 2004; Gabernet et al., 2005; Katz et al., 2006). However, cortical cells exhibit slower and more substantial adaptation (Ahissar et al., 2001; Garabedian et al., 2003; Khatri et al., 2004; Derdikman et al., 2006), which probably results from short-term depression of thalamocortical synapses (Chung et al., 2002; Castro-Alamancos, 2004; Katz et al., 2006). In vitro cortical recordings in thalamocortical slices (Beierlein et al., 2003; Gabernet et al., 2005) suggest that inhibition adapts more than excitation. Therefore, the time window for the integration of excitation increases during repetitive whisker stimulation, which in turn may reduce the precision of cortical firing. However, no effect on the balance between excitation and inhibition was found in an in vivo study (Higley and Contreras, 2006). Thus, different views on the effect of adaptation on the balance between excitation and inhibition were supported experimentally.

Herein, we patched cells in layer 4 of the barrel cortex of anesthetized rats and recorded the responses to repetitive whisker stimulations. Similarly to other studies, we estimated the change in sensory evoked excitation and inhibition from the average response obtained at different levels of current injection (Anderson et al., 2000; Priebe and Ferster, 2005; Wilent and Contreras, 2005). Although both the excitatory and the inhibitory evoked synaptic conductances adapted, our results show that the balance is gradually skewed toward excitation. Moreover, we found that 
the balance is maintained for several stimuli before the shift becomes significant, which seems to settle the controversy surrounding this topic.

\section{Materials and Methods}

Animal preparations and recordings. Animal surgeries and in vivo recordings were performed as previously described (Katz et al., 2006). Briefly, recordings were made from young adult Wistar rats (4-7 weeks old). After initial anesthesia with ketamine $(100 \mathrm{mg} / \mathrm{kg})$ and acepromazine maleate $(1 \mathrm{mg} / \mathrm{kg})$, a tracheotomy was performed after local subcutaneous injection of lidocaine. Rats were mounted in a stereotaxic device and respirated with a mixture of halothane $(0.5-1.5 \%)$ and air. Two additional layer 4 cells were recorded from one animal that was anesthetized with isofluorane $(0.5-1 \%)$. Because no qualitative difference was observed, these two cells were pooled together with the rest of the recorded neurons. The levels of end-tidal $\mathrm{CO}_{2}$ and heart rate $(250-450$ beats/min) were monitored throughout the experiment. Body temperature was kept at $37^{\circ} \mathrm{C}$ using a heating blanket and rectal thermometer. The anesthesia level was kept between stages III-2 and III-3 [see (Katz et al., 2006)]. A craniotomy (0.5-1 $\mathrm{mm}$ in diameter) was made above the barrel cortex (centered $2.2 \mathrm{~mm}$ posterior and $5 \mathrm{~mm}$ lateral to bregma) and a portion of the dura mater was carefully removed. For extracellular thalamic recordings the craniotomy was centered $3 \mathrm{~mm}$ lateral and $3 \mathrm{~mm}$ posterior from bregma. All surgical and experimental procedures were conducted in accordance with the regulations of the Weizmann Institute Animal Care and Use Committee.

Recording techniques. Whole cell patch recordings were performed as previously described (Katz et al., 2006). Borosilicate micropipettes were pulled to produce electrodes with a resistance of $4-8 \mathrm{M} \Omega$, and filled with an intracellular solution containing (in $\mathrm{mM}$ ): $136 \mathrm{~K}$-gluconate, $10 \mathrm{KCl}, 5$ $\mathrm{NaCl}, 10$ HEPES, $1 \mathrm{MgATP}, 0.3 \mathrm{NaGTP}$, and 10 phosphocreatine (310 $\mathrm{mOsm})$. For histological identification of the recorded cells, $0.4 \%$ biocytin was added to the solution, and QX-314 (2 mM) was added to prevent action potentials. At the beginning of whole-cell recordings the total series resistance was $68 \pm 37 \mathrm{M} \Omega$ (average $\pm \mathrm{SD}, n=54$ ). Whole-cell patch recordings were obtained in current-clamp mode, and electrodes were inserted perpendicularly to the cortex, which was covered by warm $3.5 \%$ agar in standard saline. Intracellular signals were acquired using an Axoclamp-2B amplifier (Molecular Devices) and low passed at $3 \mathrm{kHz}$ before being digitized at $15 \mathrm{kHz}$. Thalamic extracellular recordings were obtained at depths of 4.7-5.2 mm (vertical penetrations) using high impedance (20-30 M $\Omega$ ) borosilicate micropipettes filled with standard ACSF. Extracellular signals were amplified using an Axoclamp-2B amplifier, bandpass filtered at $500 \mathrm{~Hz}$ to $5 \mathrm{kHz}$ using a Cornerstone EX4400 amplifier (Dagan Corp.) and digitized at $25 \mathrm{kHz}$. Local field potentials (LFP) in layer $4(850-980 \mu \mathrm{m})$, presented in the supplemental material, were recorded by tungsten electrodes (0.5-1 M $\Omega$; Alpha Omega Engineering), amplified (gain: 2500; band: $1-350 \mathrm{~Hz}$ ) by MCP plus 8 (Alpha Omega Engineering) and digitized at $5 \mathrm{kHz}$.

Whisker stimulation. Whiskers were trimmed to a length of $10-20 \mathrm{~mm}$. The whisker chosen for stimulation was inserted into a $2 \mathrm{~mm}$ plastic cone (made from a Microloader; Eppendorf) that was glued into a metal pipette $(2 \mathrm{~cm}$ portion of a 20 gauge needle) attached to the piezoelectric wafer (T220-H4-203Y; Piezosystems) which was driven by a home made controller. The displacement, rise time, and velocity (measured from $10 \%$ to $90 \%$ of the maximal amplitude) at the tip of the metal pipette were measured off-line using an optical displacement measuring system (optoNCDT 1605; Micro-Epsilon). A fast-rising voltage command was used to evoke a fast whisker deflection with a constant rise time of $\sim 1 \mathrm{~ms}$ followed by a $20 \mathrm{~ms}$ ramp-down signal that returned the whisker to the baseline position before the next command was delivered in the stimulation train. Because of the fixed rise time, amplitude and speed of deflection grow together with the magnitude of the voltage command, following a quasi-linear relationship. The stimulation velocity and the corresponding deflection amplitude were adjusted to evoke clear subthreshold response in the cortical cells and they were in the range of $20-65 \mathrm{~mm} / \mathrm{s}(20-60 \mu \mathrm{m}$ in amplitude). For a detailed description of the whisker stimulation protocol see (Katz et al., 2006). The principal whis- ker was identified after carefully mapping the receptive field of the recorded neuron by applying a short train of $5 \operatorname{stimuli}(18 \mathrm{~Hz})$ every $2 \mathrm{~s}$. For conductance measurements during repetitive whisker deflections, each cell was stimulated by a train of 20 whisker deflections at either 10 or 18 Hz. Repeating trails (29-51) of stimulation trains were delivered at three or four different holding currents ranging from -0.3 to $-0.6 \mathrm{nA}$. In thalamic recordings we used two distinct whisker deflection strengths of $6 \mathrm{~mm} / \mathrm{s}(5.5 \mu \mathrm{m}$ in amplitude) and $168 \mathrm{~mm} / \mathrm{s}$ ( $142 \mu \mathrm{m}$ in amplitude). The direction of whisker deflection was always caudorostral. All trials were pseudo-randomized with an intertrial interval of $3 \mathrm{~s}$.

Estimation of the evoked conductance. Evoked changes in the average excitatory and inhibitory synaptic conductances $\left(G_{\mathrm{e}}\right.$ and $\left.G_{\mathrm{i}}\right)$ were estimated in current clamp mode, based on methods described in previous studies (Priebe and Ferster, 2005; Wilent and Contreras, 2005). The average voltage at each time step (smoothed and subsampled at $5 \mathrm{kHz}$ ) and its derivative, were fit by the membrane potential equation: $I=C\left(d V_{\mathrm{t}} / d t\right)$ $+G_{\mathrm{r}}\left(V_{\mathrm{t}}-E_{\mathrm{r}}\right)+G_{\mathrm{e}}\left(V_{\mathrm{t}}-V_{\mathrm{e}}\right)+G_{\mathrm{i}}\left(V_{\mathrm{t}}-V_{\mathrm{i}}\right)$, where $I$ is a vector of the injected currents and $C$ is the estimated capacitance of the cell. Voltagedependent conductances not blocked by QX-314 were partially accounted for by calculating the resting conductance in the absence of stimulation $\left(G_{\mathrm{r}}\right)$ as the leak conductance corresponding to each current step. $V_{\mathrm{t}}$ is the measured membrane potential for every holding current at each time step, corrected for the series resistance $\left(R_{\mathrm{s}}\right)$, junction potential (which we measured to be approximately $-12 \mathrm{mV}$ ), and slow voltage drifts. The instantaneous derivative of the voltage $\left(d V_{\mathrm{t}} / d t\right)$ was approximated by $\Delta V / \Delta T$, where $\Delta V$ is the difference between 2 consecutive voltage samples, and $\Delta T$ is the time between them $(1 / 5000 \mathrm{~s})$. The cell capacitance, $C$, and $R_{\mathrm{s}}$ were estimated by fitting the average voltage, at the end of the injection of the holding current, to the analytical solution of the response of the electrical circuit to a step of current. The $R_{\mathrm{s}}$ was then validated and, when necessary, adjusted by visual inspection of the corrected voltages to eliminate only the fast component of the voltage change after the current step. $E_{\mathrm{r}}$ is the average membrane potential at rest, $V_{\mathrm{e}}$ is the reversal potential of excitation (assumed to be $0 \mathrm{mV}$ ), and $V_{\mathrm{i}}$ is the reversal potential of inhibition (assumed to be $-80 \mathrm{mV}$ ). Two unknowns $\left(G_{\mathrm{e}}\right.$ and $\left.G_{\mathrm{i}}\right)$ were estimated by linear regression. The accuracy of the estimated conductances was verified by reconstructing changes in voltage (Priebe and Ferster, 2005) based on the membrane potential equation, and are presented together with the actual measured potentials (see Figs. 3, 4).

Analysis of latencies, peak conductances, and confidence intervals. Onset of responses and evoked conductances were measured when the values reached $15 \%$ of the difference between peak amplitude and the local minima, which occurred between $4 \mathrm{~ms}$ after the stimulus and the beginning of the response. For each stimulus in a train, the amplitude of the evoked conductance was estimated as the mean of a $1 \mathrm{~ms}$ window around the peak value. Recording quality was evaluated every 10 trials by checking that the average amplitude of the first response of the train did not change substantially.

Confidence intervals for evoked conductances and for ratio of inhibition to excitation were estimated by bootstrap. Given a cell with $n$ trials, 1000 sets of trials were formed by randomly selecting also $n$ trails from the original set, but allowing repetitions. The average conductances were calculated as described above for each of the 1000 sets. For each time step, the 1000 conductance values were sorted, and a 95\% confidence interval was determined (the values of the 2.5 and 97.5 percentiles were selected as limits). The confidence interval of the evoked balance (ratio of inhibition to excitation) was determined in a similar manner. Thalamic peristimulus time histograms (PSTHs) were obtained with $1 \mathrm{~ms}$ bins. For each unit at least 100 repeats of a train of whisker deflections were used.

Histology. At the end of the experiment, the rat was over-anesthetized with an additional doze of ketamine-acepromazine (same as the initial) and the level of halothane was increased by $1 \%$ for $2-3 \mathrm{~min}$. The animal was then perfused transcardially with $2.5 \%$ paraformaldehyde (PFA), after which the brain was removed and postfixed in PFA for $24 \mathrm{~h}$. 30\% sucrose was added for cryoprotection and after additional $24 \mathrm{~h}$, the brain was sectioned, at a plane midway between coronal and sagittal $\left(45^{\circ}\right)$, into 50 - to $100-\mu \mathrm{m}$-thick slices. Barrels were identified by cytochrome oxidase staining and cells were reconstructed by performing diaminobenzi- 
A
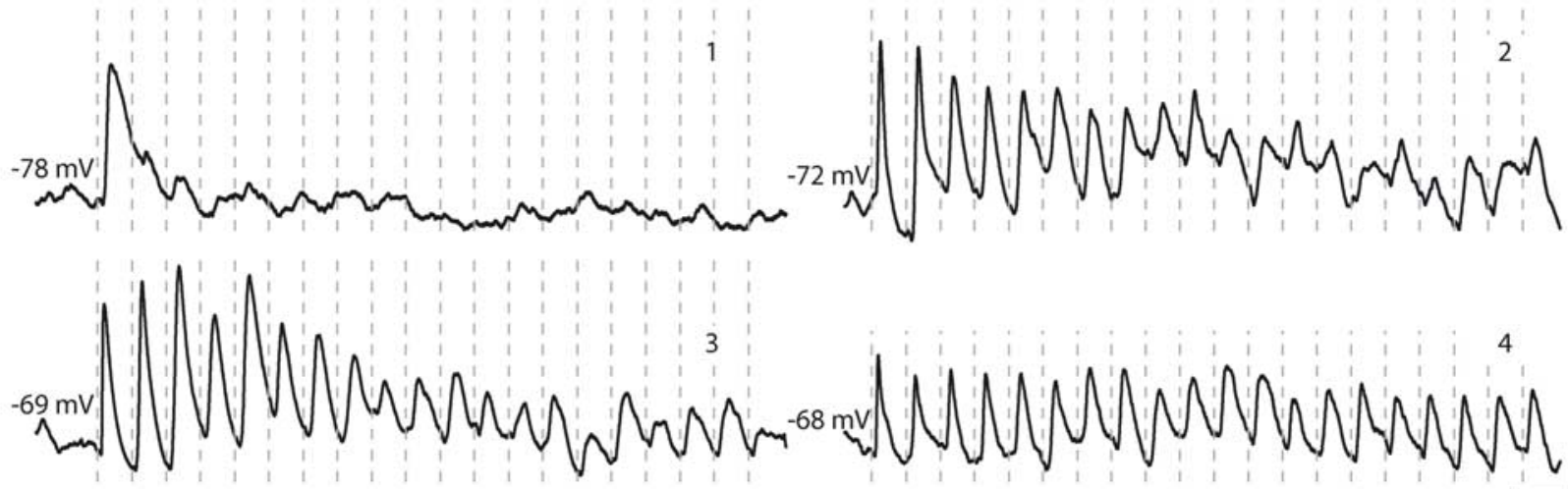
$3 \mathrm{mV}$

B
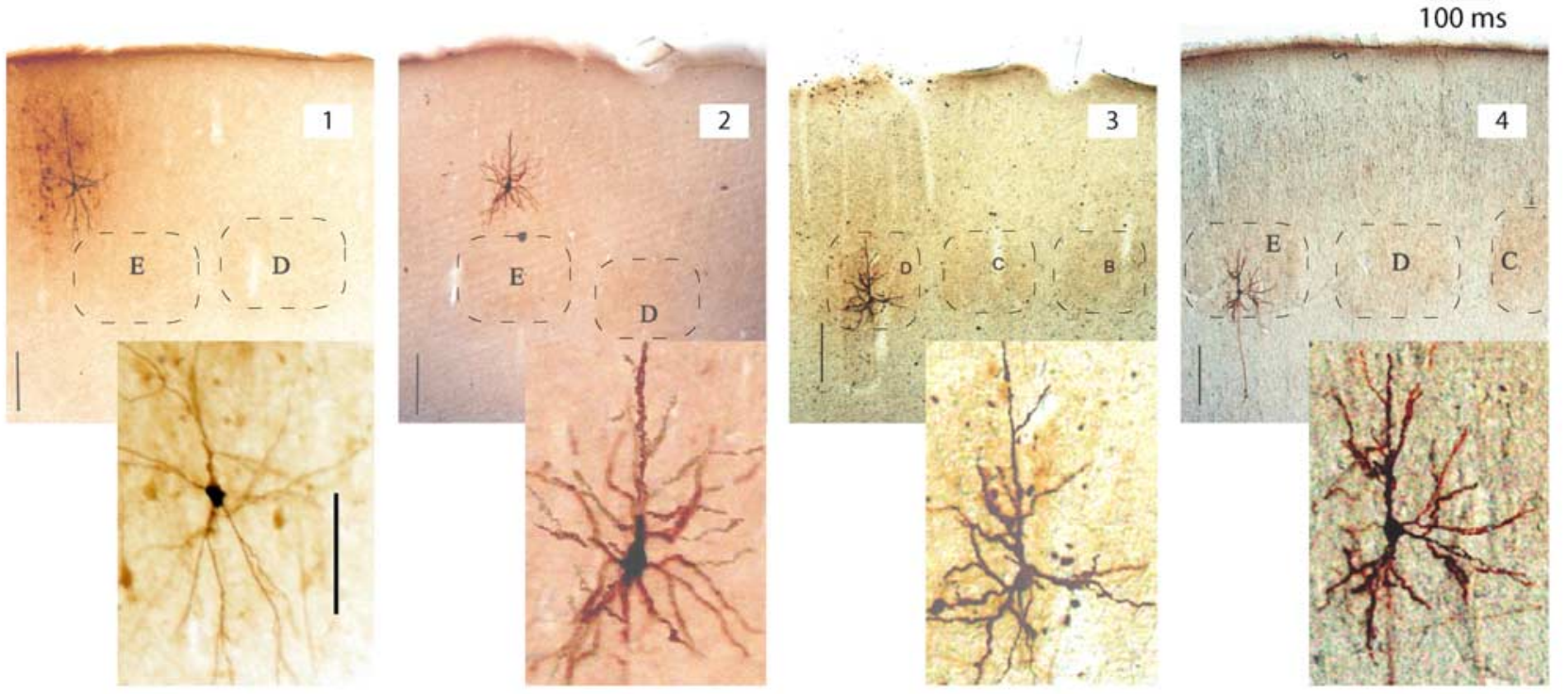

C
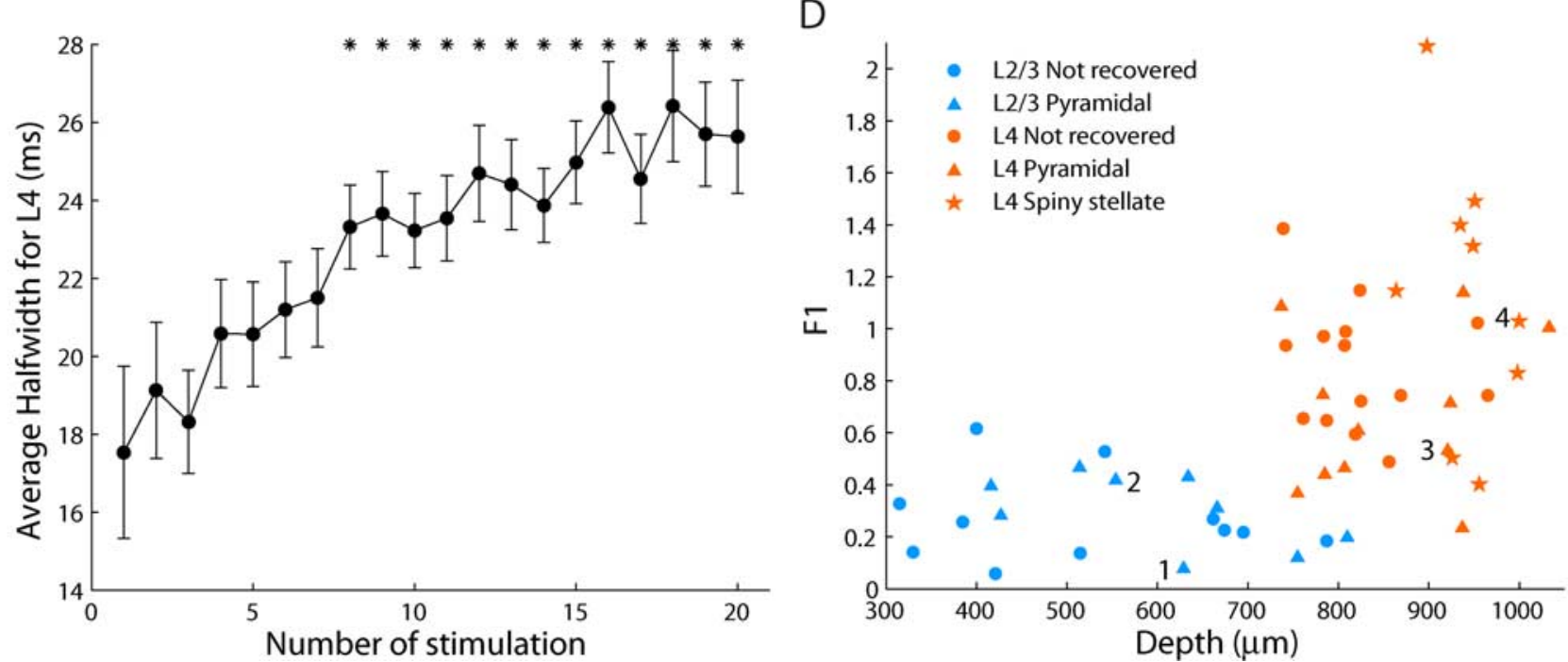

Figure 1. Subthreshold response to repetitive whisker stimulation in the barrel cortex.A,Average membrane potential during $18 \mathrm{~Hz}$ whisker stimulation in the barrel cortex. Cells 1 and 2 are from layer $2 / 3$ and cells 3 and 4 are from layer 4 . Vertical dashed lines represent times of whisker deflection. $\boldsymbol{B}$, Histological reconstruction of the recorded neurons. Cells $1-3$ are pyramidal and cell 4 is spiny stellate. Black bars correspond to $200 \mu \mathrm{m}$ after tissue fixation. Insets are enlarged images of the respective neurons. All of the inset images are in the same scale (scale bar in inset of cell 1 corresponds to $50 \mu \mathrm{m})$. C, The average half-width of the synaptic potential response increases during repetitive stimulation. Asterisks denote highly significant differences with respect to the first stimulation $(p<0.01), n=25$. Error bars are SEM. $\boldsymbol{D}$, Responsiveness index (F1) plotted versus the recording depth (manipulator readout) for all recorded cells. Numbered cells (1-4) are the illustrated neurons.

dine (DAB) staining in the same slice, as described previously (Katz et al., 2006). Neurons morphologically identified as septa cells (between barrels) or suspected as inhibitory cells (i.e., had a small soma and no spines) were not included in the study $(n=3)$. Cells seen in multiple slices were merged in a single picture using Adobe Photoshop (Fig. 1, cells 2-4). Because of some variability in the location of the barrels, the depth of the recording is not always sufficient to determine laminar position. For example, in this study, reconstructed layer $2 / 3$ cells were found as deep as 
A

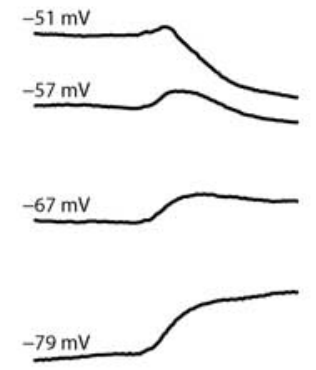

$C$

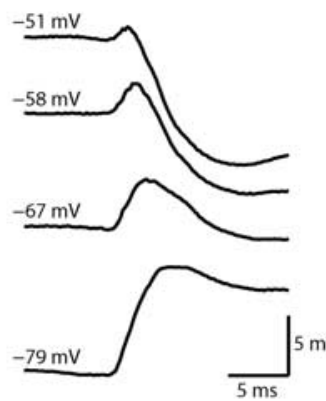

B $\mathrm{Gi} / \mathrm{Ge}=2.9$
$27 \mathrm{~mm} / \mathrm{s}$ $24.5 \mu \mathrm{m}$

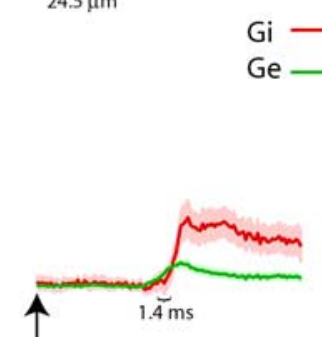

D $\mathrm{Gi} / \mathrm{Ge}=4.6$
$54 \mathrm{~mm} / \mathrm{s}$ $54 \mathrm{~mm} / \mathrm{s}$
$49.9 \mu \mathrm{m}$
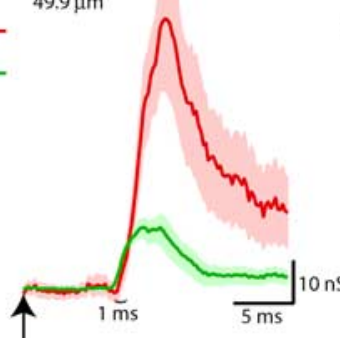

$\mathrm{E}$

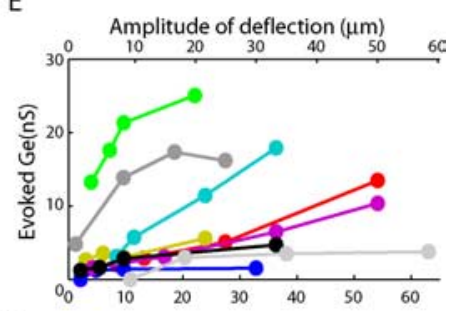

$\mathrm{F}$

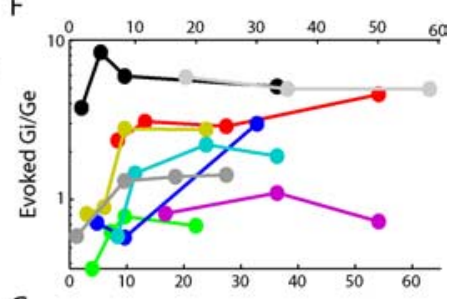

G

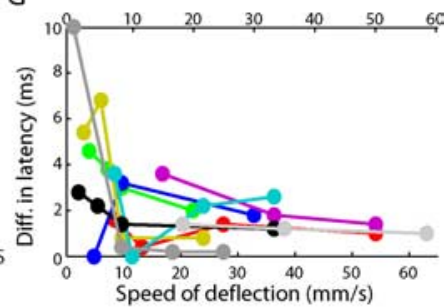

Figure 2. Effects of the strength of whisker deflection on the timing and ratio between inhibition and excitation. $A, C$, Averaged subthreshold response of a layer 4 cell at two different strengths of whisker deflection, recorded at four different levels of current injection. $\boldsymbol{B}, \boldsymbol{D}$, Corresponding excitatory and inhibitory conductances evoked by two strengths of stimulation. Shaded areas are the $95 \%$ confidence interval. The time of stimulation is marked by arrows and the curly brackets approximately indicate the time lag (in ms) between excitation and inhibition, based on the values at $15 \%$ of the peak. $E-G$, Evoked excitatory conductance $\left(G_{\mathrm{e}}\right)$, evoked balance (the ratio between peak inhibition and peak excitation, $G_{i} / G_{e}$ ), and difference in latency between excitatory and inhibitory onsets of layer 4 cells measured at four different stimulation strengths $(n=9)$. A different color is used for each cell. Red curves correspond to the cell presented in $\boldsymbol{A}-\boldsymbol{D}$.

$810 \mu \mathrm{m}$, whereas the most superficial reconstructed layer 4 cell was found at a depth of $737 \mu \mathrm{m}$. Cells that were not reconstructed histologically were classified according to the depth of the microelectrode and recording parameters as follows. Cells were classified as putative layer 4 barrel neurons if they were recorded at a depth (between 800 and 970 $\mu \mathrm{m})$ at which the barrel band always stained, and if their latency to principal whisker (PW) deflection was $<8 \mathrm{~ms}$, which included delays of the piezoelectric wafer and its controller. If the depth of the recorded cell was $<730 \mu \mathrm{m}$, it was considered to be a layer $2 / 3$ cell; in all of these cases, the cells had a latency $>8 \mathrm{~ms}$. Nonreconstructed cells (five in putative layer 4 and one in putative layer 2/3) located at a depth between 730 and $800 \mu \mathrm{m}$ were classified as layer $2 / 3$ or 4 based on their latency. One nonreconstructed cell that was found at a depth between 800 and 970 $\mu \mathrm{m}$, and which had a latency $>8 \mathrm{~ms}$, was discarded as a suspected septa cell.

Statistical tests. For establishing the significance level when comparing two sets of magnitudes, Mann-Whitney $U$ test (Wilcoxon rank sum test) was used. When testing whether the median of a normalized data were different from $100 \%$, we used two-sided Wilcoxon signed rank test.

\section{Results}

\section{Adaptation of evoked synaptic potentials in granular and} supragranular layers

Response to repetitive stimulation of the principal whisker at 18 $\mathrm{Hz}$ was recorded intracellularly from layers $2 / 3(n=20)$ and 4 $(n=34)$ in the primary somatosensory cortex of the rat. All of the cells were recorded with QX-314, which allowed us to study the evoked synaptic potential in the absence of firing (Connors and Prince, 1982). Adaptation patterns at the resting potential, typically exhibited at different depths are illustrated in Figure $1 \mathrm{~A}$. A

layer $2 / 3$ neuron located in the periphery of the barrel cortex (cell 1) adapted strongly, whereas a neuron located just above the barrel (cell 2) was as responsive as a pyramidal cell located inside the barrel (cell 3). A spiny stellate cell located in the lower part of the barrel (cell 4) responded with almost no apparent adaptation. Although this cell demonstrated almost constant amplitude throughout the train, the width of the synaptic potentials increased drastically during the train. A significant widening of the synaptic response was measured, from a half-width of $17.5 \pm 2.2$ $\mathrm{ms}$ for the first stimulation, to $25.6 \pm 1.5$ ms for the last (Fig. 1C) $(n=25, p=$ 0.0013 , average \pm SEM).

To obtain a robust measure of adaptation at the resting potential of the cells, we calculated a responsiveness index (F1) using Fourier analysis of the average response (Katz et al., 2006). Briefly, the power of the average response at the stimulation frequency $(18 \mathrm{~Hz})$ was divided by its corresponding value in an ideal, nonadapted signal, constructed by replicating the first response throughout the entire train. The smaller this index, the more adapted the response is considered. Consistent with previous studies of adaptation in the barrel cortex (Ahissar et al., 2001), the $\mathrm{F} 1$ of layer 4 cells (average $\pm \mathrm{SD}$; $0.87 \pm 0.39, n=34)$ was significantly $(p=$ $\left.4.9 \times 10^{-8}\right)$ larger than that of layer $2 / 3$ cells $(0.28 \pm 0.15, n=20)$, which indicates that layer 4 cells adapt less (Fig. $1 D$ ). Histologically reconstructed pyramidal cells of layer 4 (average F1 values of $0.67 \pm 0.30, n=$ 11) adapted more ( $p=0.033)$ than suspected spiny stellate cells $(1.13 \pm 0.52, n=9)$, consistent with another in vivo intracellular study of the barrel cortex (Brecht and Sakmann, 2002).

\section{The balance between excitation and inhibition depends on the strength of whisker deflection}

According to several studies, adaptation during repetitive whisker stimulation results from short-term synaptic depression of thalamocortical synapses (Brecht and Sakmann, 2002; CastroAlamancos, 2002; Beierlein et al., 2003; Khatri et al., 2004; Katz et al., 2006). If this holds true, the strength of thalamic inputs would be weakened during repetitive sensory stimulation. Thus, we varied the strength of whisker deflection and measured its effects on excitation and inhibition in 9 cells, for eventual comparison with the effects of repetitive whisker stimulation. Because the rise-time of the stimulation was constant, the speed and the amplitude of the deflection were almost linearly correlated when the strength (voltage command) of stimulation was changed (see Materials and Methods). Estimation of the evoked excitation and inhibition was obtained by averaging the responses to different strengths of whisker deflection, at four different levels of current injection (Fig. $2 A-D$ ). Stimulation strength had two major effects on the relation between excitation and inhibition: strong stimulation evoked more inhibition relative to excitation (Fig. $2 F$ ), and although excitation always preceded inhibition, the time lag between the onset of excitation and the onset of inhibition 
shortened at stronger stimulations (Fig. 2G). Although the effects of stimulation strength on the balance and on the lag almost saturated at relatively weak stimulation $(\sim 10 \mathrm{~mm} / \mathrm{s})$, evoked excitatory conductance kept increasing with strength (Fig. 2 E). The range of stimulation strengths is different for each cell because it was adjusted to reveal clear and different response for at least three strengths. Yet, on average, when the measurements were normalized using the values obtained with the strongest stimulation, the weakest stimulation evoked $41 \pm 26 \%$ (average \pm SD; median 30\%) of the excitation evoked by the strongest stimulation, $60 \pm 35 \%$ (median 51\%) of the ratio (the balance) between inhibition and excitation, and $300 \pm 195 \%$ (median $275 \%$ ) of the lag between inhibition and excitation ( $p$ values of $0.004,0.02$, and 0.012 , respectively, $n=9$ ). Thus stimulation strength has a significant effect not only on the amount of evoked excitation, which was expected, but also on the balance between excitation and inhibition and on the relative timing of these synaptic components.

We suspected that the reduced ratio between inhibition and excitation, and the increased lag of inhibition relative to excitation are gain mechanisms that increase the efficacy of excitation at weak stimulation, despite a smaller excitatory input. In fact, the average amplitude of the response for the weakest stimulation at resting potential, $(7.2 \pm 1.6 \mathrm{mV})$ was not significantly smaller $(p$ $=0.44)$ than that for the strongest stimulation $(9.2 \pm 2.2 \mathrm{mV}$; supplemental Fig. S1 A, available at www.jneurosci.org as supplemental material). The large change in the balance and timing were accompanied by a significant widening (from $4.2 \pm 0.8 \mathrm{~ms}$ to $15.9 \pm 4.1 \mathrm{~ms}, p=0.03$ ) of the half-width of the PSP for the weak stimulus (measured at $0.1-0.2 \mathrm{nA}$ of depolarization) (supplemental Fig. S1B, available at www.jneurosci.org as supplemental material). Values above are average \pm SEM.

\section{Inhibition adapts more than excitation}

Because thalamocortical inputs are probably weakened during repetitive sensory stimulation as a result of synaptic depression, effects similar to those occurring when stimulation strength is reduced were expected. In particular we anticipated a decrease in evoked excitation and a skew in the excitation-inhibition balance. A single trial-recording of a suspected spiny stellate cell at its resting potential shows that early during the $18 \mathrm{~Hz}$ train of whisker stimulation, the responses were narrow, rising and decaying rapidly (Fig. $3 A$, upper trace). After several stimuli, wider and slower responses were evoked, especially at their falling phase. Upon depolarization with a current injection of $0.3 \mathrm{nA}$ in a different trial (Fig. $3 A$, lower trace), each stimulus during the early part of the train evoked a small depolarizing potential, which was followed by a large negative potential. These large negative potentials gradually became smaller, and completely disappeared around the $10^{\text {th }}$ stimulus, after which only slow and wide depolarizing potentials were evoked. This observed change in direction of potentials during the train on depolarization suggests that responses during the early part of the train are dominated by strong inhibition, whereas toward the end of the train, the contribution of inhibition relative to excitation becomes significantly smaller.

Evoked changes in excitation and inhibition at each time point in the response (see Materials and Methods), were estimated by fitting the averaged responses, obtained at four holding currents (Fig. 3B), with the membrane potential equation. Evoked changes in synaptic conductances revealed that inhibition adapts more than excitation (Fig. 3C). Whereas sensoryevoked excitation adapted after several deflections to a steady
A

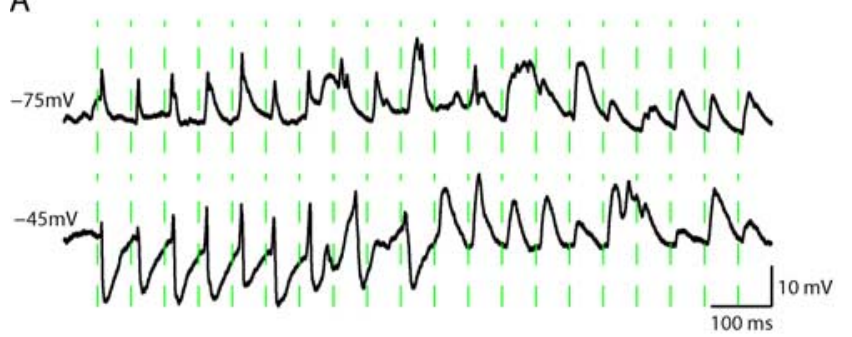

B $\quad$ Reconstructed $\longrightarrow$ Recorded

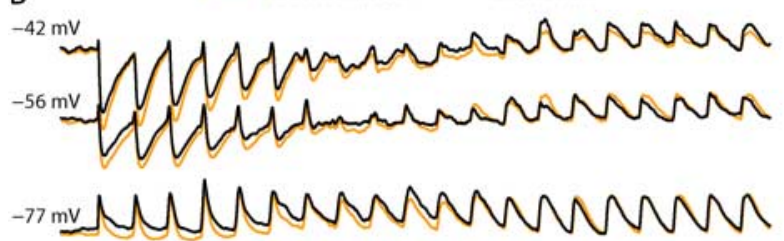

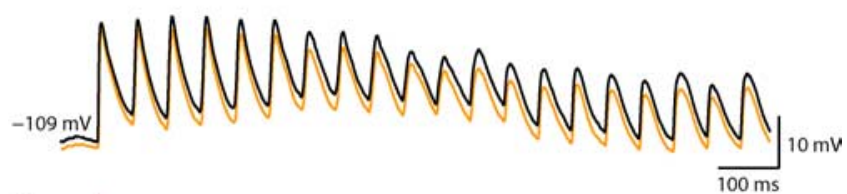

C

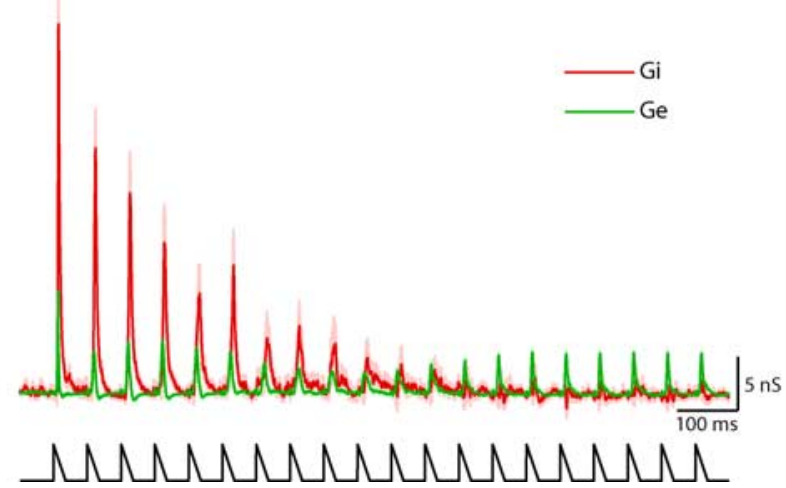

Figure 3. Measurement of excitation and inhibition evoked by repetitive whisker stimulation. $\boldsymbol{A}$, Single trial subthreshold response to repetitive whisker stimulation at rest (upper trace) and on depolarization ( $0.3 \mathrm{nA}$; lower trace). $\boldsymbol{B}$, Average responses to repetitive whisker stimulation recorded at 4 levels of current injection ( $n=50$ trials). Orange traces illustrate the voltage as was reconstructed from the conductances (see Materials and Methods). C, Estimated changes in excitatory $\left(G_{\mathrm{e}}\right)$ and inhibitory $\left(G_{\mathrm{i}}\right)$ conductances evoked by repetitive whisker stimulation. Shaded area indicates $95 \%$ confidence interval. Note that evoked inhibition adapted completely. A schematic plot of the stimulation is shown by the lower plot.

level of $\sim 50 \%$ of its initial value, the evoked inhibition in this representative cell adapted almost completely. Similar behavior, in which inhibition adapted more than excitation, is presented for the spiny stellate (Fig. $4 A$ ) and the pyramidal (Fig. $4 B$ ) cells of layer 4 shown in Figure 1 (cells 3 and 4 ). The quality of the linear model-fit for the estimated changes in conductance is evident from the similarity of the recorded and reconstructed responses (Figs. $3 B, 4 A, B$ ). Variations of up to $20 \mathrm{mV}$ in the assumed reversal potentials of excitation and inhibition had only a small qualitative effect on our estimation of evoked conductances and in particular on the balance (supplemental Fig. S2, available at www.jneurosci.org as supplemental material).

The difference in the adaptation of evoked excitation and inhibition during repetitive stimulation was evaluated using two methods. In one, the peak values of evoked excitation and inhibition throughout the stimulation train were measured, normalized by the first response, and then averaged across all cells (Fig. $5 A$ ). During the last 4 stimuli, inhibition adapted almost com- 

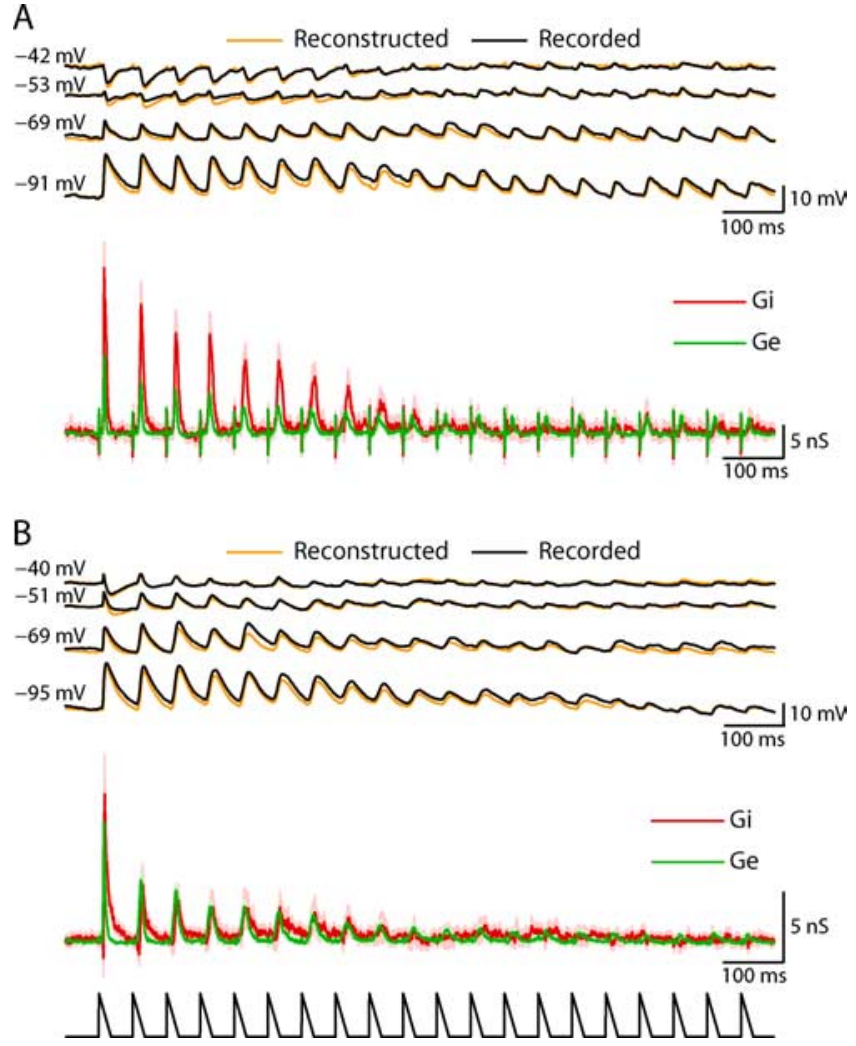

Figure 4. Averaged response and conductance estimations to repetitive whisker stimulation of two additional cells in layer 4. $\boldsymbol{A}$, Upper traces: Average responses to repetitive whisker stimulation at 4 levels of current injection ( $n=44$ trials) of a spiny stellate cell (cell 4 in Fig. 1). Orange traces illustrate the voltage reconstructed from the conductances (see Materials and Methods). Lower traces: Estimates of the changes in excitatory $\left(G_{\mathrm{e}}\right)$ and inhibitory (Gi) conductances evoked by repetitive stimulation. Shaded area indicates $95 \%$ confidence interval. $\boldsymbol{B}$ Average response (upper traces) of a pyramidal cell (cell 3 in Fig. 1) recorded at different holding currents ( 40 repeats of $18 \mathrm{~Hz}$ stimulation). Middle traces show the estimated evoked excitation and inhibition and lower trace shows a schematic plot of the whisker stimulation.

pletely and reached only $6 \pm 6 \%$ (average \pm SD) of its initial value. When compared with inhibition, excitation (which reached $23 \pm 13 \%$ of its initial value) adapted significantly less ( $p$ $=8 \times 10^{-10}$, comparison between the normalized excitation and inhibition of the averaged last 4 evoked conductances of all cells). In the other method, the F1 index of the estimated excitatory and inhibitory conductances was calculated (Fig. $5 B$ ) using the same method which was used for the voltage in Figure $1 D$. In all 34 layer 4 neurons examined, the F1 of the inhibitory conductance was smaller than that of the excitatory conductance $\left(p=10^{-9}\right)$, further suggesting that inhibition adapts more than excitation. The different adaptation dynamics of excitation and inhibition caused a change in the ratio between the evoked inhibition and excitation during repetitive stimulation (Fig. $5 C$ ). Highly significant change $(p$ value $<0.01)$ in this ratio was measured only after 6 stimuli. Furthermore, toward the end of the train (from the $13^{\text {th }}$ stimuli and on), this ratio started to stabilize.

Based on our hypothesis, that the strength of excitation reflects to some extent the strength of thalamic inputs, and our finding that the stimulation strength changes the balance between excitation and inhibition (Fig. 2), we examined the relationship between the balance $\left(G_{\mathrm{i}} / G_{\mathrm{e}}\right)$ and the strength of excitation during repetitive stimulation. Upon plotting the normalized average balance against the average evoked excitation for each stimulus (Fig. 5D), a highly nonlinear relation was revealed. Note that the $y$-axis in panels $5 C$ and $D$ are exactly the same and that the deflection numbers in Figure $5 D$, which starts from the rightmost side of the figure, are marked for every fifth stimuli. A rapid reduction in excitation occurred with the first several stimuli, reaching $<50 \%$ of its initial value at the fourth stimulation, whereas the balance remained almost constant, that is, inhibition and excitation adapted at about the same rate. After this initial period, a slow reduction in the $G_{\mathrm{i}} / G_{\mathrm{e}}$ ratio was measured. At about the $11^{\text {th }}$ deflection, excitation reached a steady level, whereas inhibition continued to adapt, which caused a vertical drop in the $G_{\mathrm{i}} / G_{\mathrm{e}}$ ratio. Toward the end of the train, inhibition also reached a steady level, indicated by the overlap of the last few data points.

Frequency-dependent adaptation of excitation and inhibition The strength of inhibition and excitation, as well as the ratio between them, decreases when the stimulation strength is reduced (Fig. 2E,F), and also during adaptation (Fig. 5A,C). Hence, we reasoned that if the ratio between inhibition and excitation during adaptation is determined by the strength of excitation, then it should be independent of stimulation frequency. In other words, if the strength of inhibition is determined by excitation only, $G_{\mathrm{i}} / G_{\mathrm{e}}$ versus $G_{\mathrm{e}}$ curves (such as the one in Fig. $5 D$ ) obtained at different frequencies should overlap. This hypothesis was tested in 12 cells of layer 4 by randomized trials of $10 \mathrm{~Hz}$ and $18 \mathrm{~Hz}$ of repetitive whisker stimulation. Stimulation trains were delivered at 3 or 4 different holding currents to estimate the changes in the evoked excitation and inhibition. During the early part of the train (first 3 deflections for $18 \mathrm{~Hz}$ and first 5 deflections for $10 \mathrm{~Hz}$ ), the dynamics of the balance were similar for the two frequencies, despite a profound reduction $(>50 \%)$ in the strength of the evoked excitation, as it can be seen in two examples of single cells (Fig. $6 A, B$ ). Later, the $G_{\mathrm{i}} / G_{\mathrm{e}}$ versus $G_{\mathrm{e}}$ curves diverged, as was also confirmed in the population data (Fig. $6 D$ ). Toward the second half of the train, excitation reached a steady level, whereas the inhibitory conductance continued to diminish, causing a large decrease in the ratio for both frequencies. The observed frequency-dependent relationship between balance and excitation reflects the difference in sensitivity of the excitatory and inhibitory pathways to stimulation frequency. However, when the balance is plotted as function of deflection number (Fig. $6 C)$, no significant differences between the two frequencies can be observed. In summary, during the early part of the train, the balance is maintained and thus it is independent of the stimulation frequency. Later, when excitation adapts in a frequencydependent manner, the balance cannot be expressed in terms of the evoked excitatory conductance alone, because for different values of excitation, the same balance can be attained in a historydependent manner. Furthermore, once the evoked excitation reaches a steady state, whereas inhibition keeps adapting, different values of balance can be obtained for the same excitatory input at a given frequency.

\section{Changes in the latency of excitation and inhibition during adaptation}

Next, we examined the temporal relation between excitation and inhibition during adaptation. Because cells in layer 4 receive direct excitatory thalamic inputs, a longer latency to the onset of excitation may reflect a change in the latency of thalamic firing. In contrast, onset of inhibition depends on the firing latency of inhibitory cortical cells. A reduction in the strength of the thalamocortical inputs of inhibitory cells may cause a longer delay in their firing, and thus, an increased lag between excitation 
and inhibition. Indeed, weaker stimulation increased this lag (Fig. $2 B, D$ ). Thus, even if the strength and onset of thalamic firing is maintained throughout the train, depression of the thalamocortical synaptic inputs of inhibitory cells is expected to increase the latency of inhibition, without changing the latency of excitation (which is determined by the latency of thalamic firing plus a synaptic delay) and thus to increase the lag between the onset of excitation and onset of inhibition. However, if adaptation occurs only at the inhibitory synapses, the latency of inhibition should remain unchanged. We therefore compared the latency to evoked firing in thalamic cells to the onset of evoked excitatory and inhibitory conductances.

The average peristimulus time histogram (PSTH) from 27 VPM units stimulated at $18 \mathrm{~Hz}$ (Fig. 7A) reveals rapid adaptation during the early part of the train, mostly between the first and second stimuli, in agreement with previous studies (Hellweg et al., 1977; Sosnik et al., 2001; Hartings et al., 2003; Khatri et al., 2004; Gabernet et al., 2005; Katz et al., 2006). The latency of the response during the train (Fig. 7B, dark green) does not change significantly from the second stimulation and on, reaching its peak $(10.1 \pm 0.5 \mathrm{~ms}$; average \pm SEM) at the fifth stimulation, and slightly reducing toward the end of the train (to a latency of $9.5 \pm 0.6 \mathrm{~ms}$ ). Similar behavior was also observed for minimal stimulation strength (Fig. $7 B$, light green curve). The resemblance in these two curves indicates that the latency of thalamic cells is only weakly dependent on stimulation strength. As expected from their direct thalamic inputs, the latency of excitation in layer 4 cells (Fig. 7C, green trace) exhibited a trend similar to that of thalamic cells (with an additional delay of $\sim 2 \mathrm{~ms}$ ), with the largest change (an increase in latency of $\sim 2$ ms) occurring during the early part of the train, followed by a moderate and slow decrease. In contrast, the onset of inhibition increased much more during the early part of the train (by $\sim 4$ ms) and exhibited less recovery. The time lag between the onsets of excitation and inhibition (Fig. 7D) increased mostly from the first to the second stimuli (from $1.2 \pm 0.2 \mathrm{~ms}$ to $3.7 \pm 0.5 \mathrm{~ms}$; average \pm SEM), and then remained almost constant throughout the train. Therefore, we suggest that the initial change in this lag reflects reduced input strength, caused by the reduction of thalamic firing (see Fig. 7A) which in turn increases the latency to the firing onset of inhibitory cells. More importantly, the lack of further gradual increase in the lag of inhibition with respect to excitation during the train, despite large and gradual adaptation of inhibition (Figs. 3-6), strongly suggests that inhibition adapted because of depression of cortical inhibitory synapses rather than reduction in the firing of inhibitory cells.

\section{Discussion}

In the rat somatosensory system, high frequency repetitive whisker stimulation reduces the firing response of cortical cells. Here, we examined the underlying synaptic mechanisms of this process by measuring excitatory and inhibitory contributions to the sub-
B

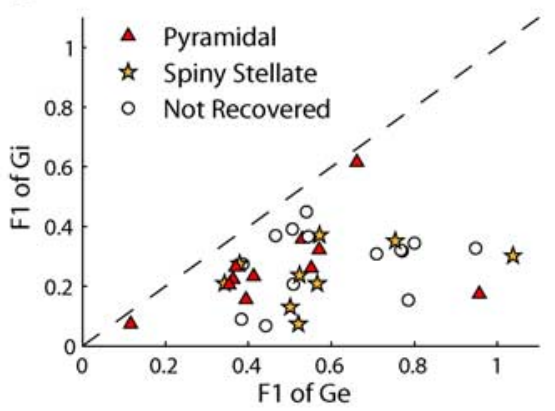

D

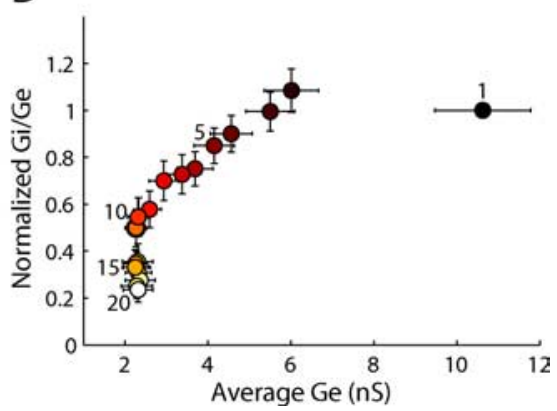

Figure 5. Dynamics of evoked excitation and inhibition during adaptation. $\boldsymbol{A}$, Population average of normalized peak excita-

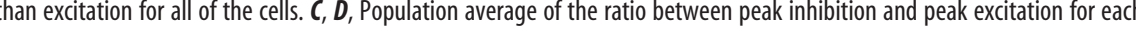
$\boldsymbol{D}$ the first deflection is at the rightmost side and the numbers above the data points indicate the deflection number. Highly significant difference with respect to the first deflection is marked by asterisks in $C(p<0.01)$. Error bars are SEM.

threshold response of layer 4 cells during repetitive stimulation of the principal whisker. We found that the balance between excitation and inhibition was altered throughout the train as a result of larger adaptation of inhibition compared with excitation. However, the lag between the onset of excitation and inhibition increased mostly between the first and second deflections, suggesting that the gradual adaptation of inhibition observed during the train results mostly from depression of the inhibitory synapses rather than from adaptation in the firing of inhibitory cells.

Our recordings were obtained with pipettes that contained QX-314 to prevent action potentials. QX-314 also blocks persistent sodium currents (Connors and Prince, 1982). At higher concentration than what we used in our experiments, QX-314 also blocks $\mathrm{I}_{\mathrm{h}}$ (Perkins and Wong, 1995) and $\mathrm{GABA}_{\mathrm{B}}$ receptors (Nathan et al., 1990). However, control recordings in the absence of QX-314 confirm that inhibition adapts more than excitation (supplemental Figure S4A, available at www.jneurosci.org as supplemental material), indicating that our results were not qualitatively affected by QX-314. Additional control experiments were performed by comparing the adaptation pattern in the local field potential (LFP) with the intracellular recording data (supplemental Figure $\mathrm{S} 4 B, C$, available at www.jneurosci.org as supplemental material).

\section{Adaptation to vibrissa stimulation}

Adaptation induced by repetitive whisker stimulation of neurons in the barrel cortex of anesthetized animals is frequency dependent (Ahissar et al., 2000; Chung et al., 2002; Castro-Alamancos, 2004; Khatri et al., 2004; Ego-Stengel et al., 2005; Gabernet et al., 2005; Higley and Contreras, 2006; Melzer et al., 2006; Webber 
A

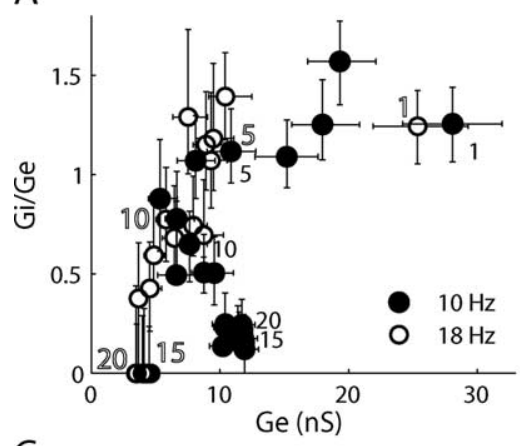

C

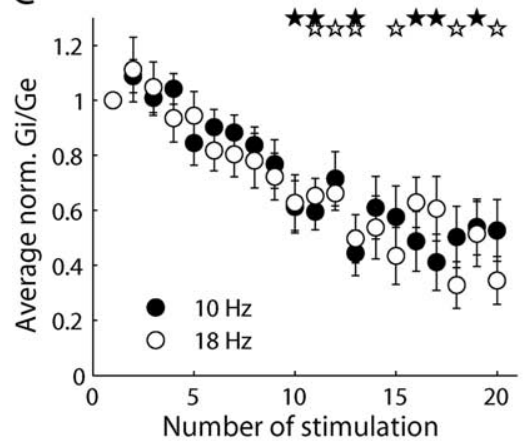

B

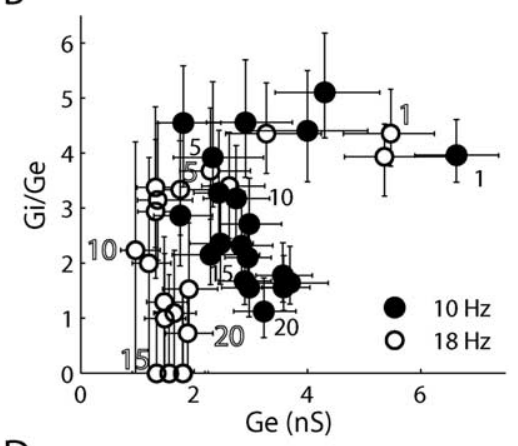

D

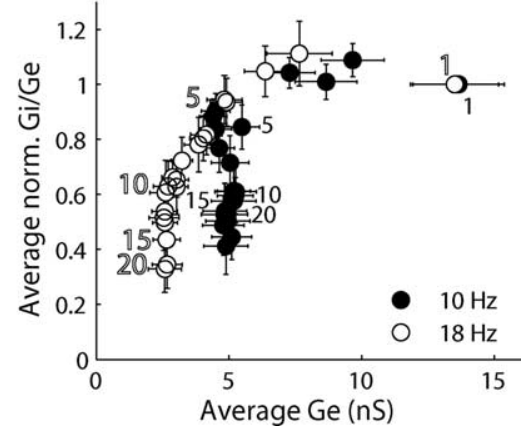

Figure 6. Balance between excitation and inhibition measured at two stimulation frequencies. $A, B$, Examples of $G_{\mathrm{i}} / G_{\mathrm{e}}$ as a function of peak evoked excitation $\left(G_{e}\right)$ measured at 10 and $18 \mathrm{~Hz}$ whisker stimulation for two different neurons. The behavior was similar, although one cell was recorded under isofluorane anesthesia $(\boldsymbol{A})$ and the other under halothane anesthesia $(\boldsymbol{B})$. Error bars denote $95 \%$ confidence interval. $\boldsymbol{C}, \boldsymbol{D}$, Population average of the ratio between inhibition and excitation (normalized for each cell by the first stimulus) plotted as a function of stimulation number $(\boldsymbol{C})$ and as a function of peak excitation $(\boldsymbol{D})$. Stars mark significant differences with respect to the first deflection ( $p<0.01)$. Error bars are SEM $(n=12)$. Numbers adjacent to the data points (every fifth stimulation) denotes the respective number of stimulation ( $10 \mathrm{~Hz}$ by filled numbers and $18 \mathrm{~Hz}$ by outlined numbers).

and Stanley, 2006). The higher the frequency of the stimulation, the stronger the adaptation. Adaptation also occurs in the VPM nucleus of the thalamus (Hellweg et al., 1977; Sosnik et al., 2001; Chung et al., 2002; Hartings et al., 2003; Khatri et al., 2004; Katz et al., 2006), but is less pronounced and reaches a steady level much faster than in the cortex (Fig. 7A). Therefore, local cortical mechanisms are probably involved in the adaptation of the response in layer 4 . In the cortex, adaptation is stronger for neurons located above the layer 4 barrels (Ahissar et al., 2000; Brecht and Sakmann, 2002; Brecht et al., 2003; Katz et al., 2006), as confirmed by the different, although overlapping, ranges of the responsiveness index for neurons in granular and supragranular layers (Fig. 1D).

Several mechanisms have been suggested to contribute to adaptation of cortical cells, including: buildup of inhibition that may shunt the responses (Dealy and Tolhurst, 1974), intrinsic voltage-dependent conductances (Carandini and Ferster, 1997; Sanchez-Vives et al., 2000), synaptic depression of thalamocortical inputs (Gil et al., 1999; Beierlein et al., 2002; CastroAlamancos, 2002; Chung et al., 2002) and short-term depression of corticocortical synapses (Petersen, 2002; Cowan and Stricker, 2004). Because adaptation is highly specific to the stimulated whisker, as we have recently demonstrated (Katz et al., 2006), it is unlikely that the first two mechanisms listed above are involved in shaping adaptation in the barrel cortex. Although the possibility that adaptation involves depression of intracortical excitatory inputs cannot be excluded, we suggest, based on the success of a feedforward model in predicting the dynamics of the balance between excitation and inhibition (supplemental Fig. S3, available at www.jneurosci.org as supplemental material) that the ef- fect of the recurrent cortical network is either negligible or linear with respect to the thalamic input.

Several studies suggested that cortical adaptation in awake animals is much less pronounced. When spontaneous activity increases in awake animals, thalamocortical synapses are already at a depressed state and hence adaptation to sensory stimulation may be negligible (CastroAlamancos, 2004; Boudreau and Ferster, 2005). However, neuromodulators may depolarize depressed inhibitory cells, which would allow them to reach the firing threshold (Swadlow and Gusev, 2001). Hence, the mechanisms we describe here may play an important role in awake animals undergoing whisker stimulation at higher frequencies, which occurs, for example, during encoding of texture (Arabzadeh et al., 2005; Maravall et al., 2007).

\section{Stereotypic excitation-inhibition sequences after whisker stimulation} The balance of excitation and inhibition, as well as their temporal relation, are probably involved in determining the firing precision and rate of cortical cells. In agreement with others (Wehr and Zador, 2003; Tan et al., 2004; Wehr and Zador, 2005; Wilent and Contreras, 2005; Higley and Contreras, 2006; Wu et al., 2006), we observed that sensory stimulation evokes a stereotypic activation of excitation that was closely followed by a strong inhibition. The stronger inhibitory conductance, relative to the excitatory input, may reflect the larger unitary excitatory post synaptic current (EPSC) of impinging thalamic inputs on inhibitory neurons compared with those that impinge on excitatory cells (Porter et al., 2001; Cruikshank et al., 2007) and the robust firing of fast-spiking neurons during whisker stimulation (Swadlow and Gusev, 2000; Bruno and Simons, 2002).

\section{Possible mechanisms of skewed excitation-inhibition balance during adaptation}

Adaptation in the barrel cortex has a profound effect on the balance between excitation and inhibition. Reminiscent of this skewed balance is an intracellular study in auditory cortex, in which the ratio of inhibition to excitation evoked by a click stimulation was often smaller if presented shortly after another click (Wehr and Zador, 2005). In contrast to our findings, no significant change in the balance between excitation and inhibition in layer 4 cells was seen in the only previously reported in vivo study that measured conductance changes during repetitive whisker stimulation (Higley and Contreras, 2006). In their experiments, whiskers were stimulated with a train of 10 stimuli at $10 \mathrm{~Hz}$ (compared with 20 stimuli in our experiments). However, at 10 $\mathrm{Hz}$, we found that the balance was maintained for the first several deflections before detectable and significant skewing (Fig. 6C). Moreover, in that study the anesthetic used was isofluorane and we found very similar dynamics of the evoked excitatory and inhibitory activity for two layer 4 neurons recorded under this anesthetic compared with what was found under halothane. The 
evoked balance for 10 and $18 \mathrm{~Hz}$ of one of these cells is shown in Figure 6A and its average evoked conductance and membrane potential are shown in supplemental Figure S5, available at www.jneurosci.org as supplemental material. Hence, the differences between the findings of the studies may be the result of other factors, such as the differences in stimulation strength and stimulus shape (inverse ramp versus 1 ms square pulse), as well as the age of the rats, which were younger in our study.

The stronger adaptation of inhibition relative to excitation, i.e., the shift in the balance toward excitation, may reflect one, or more, of the following feedforward mechanisms: profound depression of thalamocortical inputs of inhibitory cells; inability of inhibitory cells to sustain firing at the stimulation frequency; and strong synaptic depression of the inhibitory synapses in layer 4 . The first possibility, profound depression of thalamocortical inputs of inhibitory cells, is strongly supported by studies of thalamocortical slices (Beierlein et al., 2003; Gabernet et al., 2005), in which thalamic inputs of inhibitory cells were depressed more than the thalamic inputs of excitatory cells. Depression of thalamic inputs of inhibitory neurons is likely to reduce the fraction of recruited inhibitory cells that fire at each subsequent stimulus. In fact, reduced strength of thalamic input, when stimulation strength is reduced, skews the balance between excitation and inhibition toward excitation (Fig. 2 F). The strength of stimulation also profoundly affected the lag between the onsets of excitation and inhibition (Fig. 2G). Because layer 4 cells receive direct thalamic inputs, changes in the onset of excitation during adaptation probably reflect changes in the timing of firing in thalamic cells (Fig. 7B). Likewise, changes in the onset of inhibition probably reflect changes in the onset of firing of inhibitory cells. If thalamic inputs become profoundly depressed, the postsynaptic response is reduced and hence the latency to firing of inhibitory cells is expected to increase. Because the onset of excitation, which is determined by the onset of thalamic firing, is unlikely to be affected by thalamocortical depression (as we confirmed in Fig. 7), an increase in the lag between excitation and inhibition is expected. However, during repetitive stimulation, the lag between excitation and inhibition increased mostly only after the first stimulus (Fig. 7D), which suggests that reduction in thalamic strength and consequently a change in the lag of inhibition relative to excitation occurs only at the very early part of the train (Fig. 7A), as a result of rapidly adapting thalamic firing (Sosnik et al., 2001; Hartings et al., 2003; Khatri et al., 2004; Katz et al., 2006).

It is unlikely that the observed shift in balance toward excitation is caused by the inability of inhibitory cells to sustain firing at the stimulation frequency, because it is known that they can fire at much higher rates (Galarreta and Hestrin, 1998). Furthermore, in vitro studies (Beierlein et al., 2003; Gabernet et al., 2005) support the involvement of strong synaptic depression of inhibitory
B

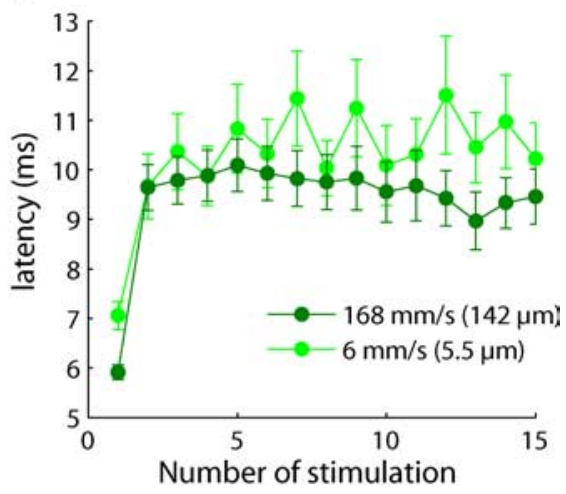

D

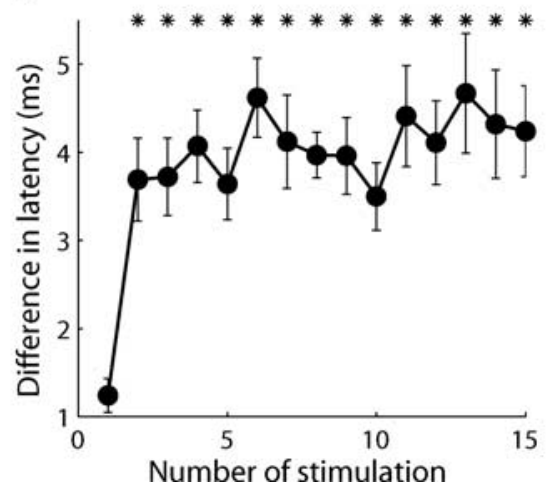

Figure 7. Latencies of thalamic firing and cortical evoked synaptic conductances during repetitive whisker stimulation. $\boldsymbol{A}$, 列 27 thalamic units stimulated at $18 \mathrm{~Hz}$ by strong whisker stimulation $(168 \mathrm{~mm} / \mathrm{s}$ with an amplitude of $142 \mu \mathrm{m})$ C, Latency of evoked excitation and inhibition at layer 4. D, Difference between the latency of evoked inhibition and of evoked excitation at layer 4 . Asterisks mark significant differences with respect to the first stimulation $(p<0.01)$. Error bars are SEM.

synapses at layer 4 under repetitive stimulation. Because inhibition adapted gradually during almost the entire train and the latency of inhibition, relative to that of excitation, did not change significantly from the second stimulation onwards (see overlapping error bars in Fig. 7D), we postulate that short-term depression of inhibitory synapses, rather than changes in sizes of recruited inhibitory populations, is critically involved in the depression of inhibition. Indeed, extracellular recordings of fast spiking units show that compared with regular spiking cells, these neurons do not adapt considerably more than thalamic units (Khatri et al., 2004; Khatri and Simons, 2007; Hirata and CastroAlamancos, 2008). The relative contribution of each of these mechanisms has yet to be determined experimentally.

The mechanisms of adaptation in the barrel cortex proposed above, describe feedforward components of layer 4 circuitry while ignoring contributions of recurrent cortical excitatory connections. In fact, comparison of our experimental data (Fig. 6) to the simulation results of a feedforward model (supplemental Fig. S3, available at www.jneurosci.org as supplemental material), in which no attempt was made to fit any of its parameters with our data, strongly suggests that the response in layer 4 and the effects of repetitive whisker stimulation can be explained at large by a feedforward circuit, consistent with findings of another intracellular study in the somatosensory cortex (Bruno and Sakmann, 2006). Another recent study, in the auditory cortex, shows a significant contribution of recurrent cortical excitation to the cor- 
tical response of layer 4 cells (Liu et al., 2007). Nevertheless, persistent activation in a recurrent network model was suggested to cause a change in balance toward excitation (Chelaru and Dragoi, 2008). In summary, the data presented here shows that adaptation to sensory stimulation in the barrel cortex is not uniform over time, and that excitation and inhibition undergo different adaptation pathways that may increase the overall gain of the circuit to persistent sensory stimulation.

\section{References}

Ahissar E, Sosnik R, Haidarliu S (2000) Transformation from temporal to rate coding in a somatosensory thalamocortical pathway. Nature 406:302-306.

Ahissar E, Sosnik R, Bagdasarian K, Haidarliu S (2001) Temporal frequency of whisker movement. II. Laminar organization of cortical representations. J Neurophysiol 86:354-367.

Anderson JS, Carandini M, Ferster D (2000) Orientation tuning of input conductance, excitation, and inhibition in cat primary visual cortex. J Neurophysiol 84:909-926.

Arabzadeh E, Zorzin E, Diamond ME (2005) Neuronal encoding of texture in the whisker sensory pathway. PLoS Biol 3:e17.

Beierlein M, Fall CP, Rinzel J, Yuste R (2002) Thalamocortical bursts trigger recurrent activity in neocortical networks: layer 4 as a frequencydependent gate. J Neurosci 22:9885-9894.

Beierlein M, Gibson JR, Connors BW (2003) Two dynamically distinct inhibitory networks in layer 4 of the neocortex. J Neurophysiol 90:2987-3000.

Berg RW, Kleinfeld D (2003) Rhythmic whisking by rat: retraction as well as protraction of the vibrissae is under active muscular control. J Neurophysiol 89:104-117.

Boudreau CE, Ferster D (2005) Short-term depression in thalamocortical synapses of cat primary visual cortex. J Neurosci 25:7179-7190.

Brecht M, Sakmann B (2002) Dynamic representation of whisker deflection by synaptic potentials in spiny stellate and pyramidal cells in the barrels and septa of layer 4 rat somatosensory cortex. J Physiol 543:49-70.

Brecht M, Roth A, Sakmann B (2003) Dynamic receptive fields of reconstructed pyramidal cells in layers 3 and 2 of rat somatosensory barrel cortex. J Physiol 553:243-265.

Bruno RM, Sakmann B (2006) Cortex is driven by weak but synchronously active thalamocortical synapses. Science 312:1622-1627.

Bruno RM, Simons DJ (2002) Feedforward mechanisms of excitatory and inhibitory cortical receptive fields. J Neurosci 22:10966-10975.

Bruno RM, Khatri V, Land PW, Simons DJ (2003) Thalamocortical angular tuning domains within individual barrels of rat somatosensory cortex. J Neurosci 23:9565-9574.

Carandini M, Ferster D (1997) A tonic hyperpolarization underlying contrast adaptation in cat visual cortex. Science 276:949-952.

Carvell GE, Simons DJ (1990) Biometric analyses of vibrissal tactile discrimination in the rat. J Neurosci 10:2638-2648.

Castro-Alamancos MA (2002) Role of thalamocortical sensory suppression during arousal: focusing sensory inputs in neocortex. J Neurosci 22:9651-9655.

Castro-Alamancos MA (2004) Absence of rapid sensory adaptation in neocortex during information processing states. Neuron 41:455-464.

Chelaru MI, Dragoi V (2008) Asymmetric synaptic depression in cortical networks. Cereb Cortex 18:771-788.

Chung S, Li X, Nelson SB (2002) Short-term depression at thalamocortical synapses contributes to rapid adaptation of cortical sensory responses in vivo. Neuron 34:437-446.

Connors BW, Prince DA (1982) Effects of local anesthetic QX-314 on the membrane properties of hippocampal pyramidal neurons. J Pharmacol Exp Ther 220:476-481.

Cowan AI, Stricker C (2004) Functional connectivity in layer IV local excitatory circuits of rat somatosensory cortex. J Neurophysiol 92:2137-2150.

Cruikshank SJ, Lewis TJ, Connors BW (2007) Synaptic basis for intense thalamocortical activation of feedforward inhibitory cells in neocortex. Nat Neurosci 10:462-468.

Dealy RS, Tolhurst DJ (1974) Is spatial adaptation an after-effect of prolonged inhibition? J Physiol 241:261-270.

Derdikman D, Yu C, Haidarliu S, Bagdasarian K, Arieli A, Ahissar E (2006)
Layer-specific touch-dependent facilitation and depression in the somatosensory cortex during active whisking. J Neurosci 26:9538-9547.

Douglas RJ, Koch C, Mahowald M, Martin KA, Suarez HH (1995) Recurrent excitation in neocortical circuits. Science 269:981-985.

Ego-Stengel V, Mello e Souza T, Jacob V, Shulz DE (2005) Spatiotemporal characteristics of neuronal sensory integration in the barrel cortex of the rat. J Neurophysiol 93:1450-1467.

Gabernet L, Jadhav SP, Feldman DE, Carandini M, Scanziani M (2005) Somatosensory integration controlled by dynamic thalamocortical feedforward inhibition. Neuron 48:315-327.

Galarreta M, Hestrin S (1998) Frequency-dependent synaptic depression and the balance of excitation and inhibition in the neocortex. Nat Neurosci 1:587-594.

Garabedian CE, Jones SR, Merzenich MM, Dale A, Moore CI (2003) Bandpass response properties of rat SI neurons. J Neurophysiol 90:1379-1391.

Gil Z, Connors BW, Amitai Y (1999) Efficacy of thalamocortical and intracortical synaptic connections: quanta, innervation, and reliability. Neuron 23:385-397.

Hartings JA, Temereanca S, Simons DJ (2003) Processing of periodic whisker deflections by neurons in the ventroposterior medial and thalamic reticular nuclei. J Neurophysiol 90:3087-3094.

Hellweg FC, Schultz W, Creutzfeldt OD (1977) Extracellular and intracellular recordings from cat's cortical whisker projection area: thalamocortical response transformation. J Neurophysiol 40:463-479.

Higley MJ, Contreras D (2006) Balanced excitation and inhibition determine spike timing during frequency adaptation. J Neurosci 26:448-457.

Hirata A, Castro-Alamancos MA (2008) Cortical transformation of widefield (multiwhisker) sensory responses. J Neurophysiol 100:358-370.

Katz Y, Heiss JE, Lampl I (2006) Cross-whisker adaptation of neurons in the rat barrel cortex. J Neurosci 26:13363-13372.

Khatri V, Simons DJ (2007) Angularly nonspecific response suppression in rat barrel cortex. Cereb Cortex 17:599-609.

Khatri V, Hartings JA, Simons DJ (2004) Adaptation in thalamic barreloid and cortical barrel neurons to periodic whisker deflections varying in frequency and velocity. J Neurophysiol 92:3244-3254.

Knutsen PM, Pietr M, Ahissar E (2006) Haptic object localization in the vibrissal system: behavior and performance. J Neurosci 26:8451-8464.

Liu BH, Wu GK, Arbuckle R, Tao HW, Zhang LI (2007) Defining cortical frequency tuning with recurrent excitatory circuitry. Nat Neurosci 10:1594-1600.

Lübke J, Egger V, Sakmann B, Feldmeyer D (2000) Columnar organization of dendrites and axons of single and synaptically coupled excitatory spiny neurons in layer 4 of the rat barrel cortex. J Neurosci 20:5300-5311.

Maravall M, Petersen RS, Fairhall AL, Arabzadeh E, Diamond ME (2007) Shifts in coding properties and maintenance of information transmission during adaptation in barrel cortex. PLoS Biol 5:e19.

Melzer P, Champney GC, Maguire MJ, Ebner FF (2006) Rate code and temporal code for frequency of whisker stimulation in rat primary and secondary somatic sensory cortex. Exp Brain Res 172:370-386.

Mittmann W, Koch U, Häusser M (2005) Feed-forward inhibition shapes the spike output of cerebellar Purkinje cells. J Physiol 563:369-378.

Nathan T, Jensen MS, Lambert JD (1990) The slow inhibitory postsynaptic potential in rat hippocampal CA1 neurones is blocked by intracellular injection of QX-314. Neurosci Lett 110:309-313.

Okun M, Lampl I (2008) Instantaneous correlation of excitation and inhibition during ongoing and sensory-evoked activities. Nat Neurosci 11:535-537.

Perkins KL, Wong RK (1995) Intracellular QX-314 blocks the hyperpolarization-activated inward current Iq in hippocampal CA1 pyramidal cells. J Neurophysiol 73:911-915.

Petersen CC (2002) Short-term dynamics of synaptic transmission within the excitatory neuronal network of rat layer 4 barrel cortex. J Neurophysiol 87:2904-2914.

Porter JT, Johnson CK, Agmon A (2001) Diverse types of interneurons generate thalamus-evoked feedforward inhibition in the mouse barrel cortex. J Neurosci 21:2699-2710.

Priebe NJ, Ferster D (2005) Direction selectivity of excitation and inhibition in simple cells of the cat primary visual cortex. Neuron 45:133-145.

Sanchez-Vives MV, Nowak LG, McCormick DA (2000) Membrane mechanisms underlying contrast adaptation in cat area 17 in vivo. J Neurosci 20:4267-4285.

Sosnik R, Haidarliu S, Ahissar E (2001) Temporal frequency of whisker 
movement. I. Representations in brain stem and thalamus. J Neurophysiol 86:339-353.

Stratford KJ, Tarczy-Hornoch K, Martin KA, Bannister NJ, Jack JJ (1996) Excitatory synaptic inputs to spiny stellate cells in cat visual cortex. Nature 382:258-261.

Sun QQ, Huguenard JR, Prince DA (2006) Barrel cortex microcircuits: thalamocortical feedforward inhibition in spiny stellate cells is mediated by a small number of fast-spiking interneurons. J Neurosci 26:1219-1230.

Swadlow HA (2003) Fast-spike interneurons and feedforward inhibition in awake sensory neocortex. Cereb Cortex 13:25-32.

Swadlow HA, Gusev AG (2000) The influence of single VB thalamocortical impulses on barrel columns of rabbit somatosensory cortex. J Neurophysiol 83:2802-2813.

Swadlow HA, Gusev AG (2001) The impact of 'bursting' thalamic impulses at a neocortical synapse. Nat Neurosci 4:402-408.
Tan AY, Zhang LI, Merzenich MM, Schreiner CE (2004) Tone-evoked excitatory and inhibitory synaptic conductances of primary auditory cortex neurons. J Neurophysiol 92:630-643.

Webber RM, Stanley GB (2006) Transient and steady-state dynamics of cortical adaptation. J Neurophysiol 95:2923-2932.

Wehr M, Zador AM (2003) Balanced inhibition underlies tuning and sharpens spike timing in auditory cortex. Nature 426:442-446.

Wehr M, Zador AM (2005) Synaptic mechanisms of forward suppression in rat auditory cortex. Neuron 47:437-445.

Wilent WB, Contreras D (2005) Dynamics of excitation and inhibition underlying stimulus selectivity in rat somatosensory cortex. Nat Neurosci 8:1364-1370.

Wu GK, Li P, Tao HW, Zhang LI (2006) Nonmonotonic synaptic excitation and imbalanced inhibition underlying cortical intensity tuning. Neuron 52:705-715. 